\title{
Differentiation of Normal and Malignant Breast Tissues using Infrared Spectroscopy
}

\author{
Ranjana Mehrotra, Deepak Kumar Jangir, Alka Gupta and H.C. Kandpal \\ Optical Radiation Standards, National Physical Laboratory, New Delhi 110 012, India.
}

\begin{abstract}
Infrared spectra of carcinomatous and their normal fore bearing tissues were collected in the $600 \mathrm{~cm}^{-1}$ to $4000 \mathrm{~cm}^{-1}$ region. Fourier Transform Infrared (FTIR) data of infiltrating ductal carcinoma of breast with different grades of malignancy from patients of different age groups were analyzed. Infrared spectra demonstrate significant spectral differences between the tumor sections of normal and the malignant breast tissues. In particular, changes in frequency and intensity in the spectra of protein, nucleic acid and glycogen were observed. This allows to make a qualitative and semi quantitative evaluation of the changes in proliferation activities from normal to diseased tissue. The findings establish a framework for additional studies, which may enable us to establish a relation of the diseased state with its infrared spectra.
\end{abstract}

Keywords: Ductal carcinoma, proliferation, Fourier Transform, Infrared Spectroscopy.

PACS: $01.30 . \mathrm{Cc}$

\section{INTRODUCTION}

Detection of cancer has primarily been base upon screening mammography followed by pathological examination of tissue samples (biopsies). To distinguish a pathological tissue from a normal one, a technique needs to sense the changed biochemistry of the cell. Nowadays high-resolution techniques are being developed for investigating initial stages of the transformation processes resulting from pathology. Among these methods vibrational spectroscopy has been employed successfully, as this technique offers possibility of qualitative as well as quantitative analysis on different chemical composition and molecular structures of healthy and diseased tissues [1]. Although the extraction of specific molecular information from such complex systems has not been fully achieved, assessment of spectra in terms of pattern recognition with sophisticated mathematical algorithms has produced promising results. Fourier Transform infrared spectroscopy (FT-IR) is being extensively used to detect and monitor the characteristic changes associated with the transformation of a normal tissue into a cancerous tissue [2-5]. Breast cancer has always been the focus of intensive study at the diagnostic as well as at therapeutic levels. Detailed studies are needed to characterize the biochemical changes occurring at molecular level in breast cancer, which can form a basis for differentiating between normal, benign and malignant tissues. The present paper deals with infrared analysis of infiltrating ductal carcinoma of breast and their comparison with normal tissues. 


\section{EXPERIMENTAL}

\section{Tissue Sampling}

Samples from twenty-five cases of breast carcinoma (infiltrating type) were analyzed for this study. After the lumpectomy / mastectomy of breast the samples of cancerous tissue and normal tissue were taken. For each case frozen $\left(-27.8^{\circ} \mathrm{C}\right)$ cryostat sections (3-4 $\mu \mathrm{m})$ were taken on Zinc Selenide crystal plates. The tissue sections were simply attached to the plates without any fixative.

\section{Infrared Spectroscopic Measurements}

FT-IR spectra of all the samples were recorded on a Bio-Rad 175 C FT-IR spectrophotometer, equipped with a deuterated triglycine sulphate detector. The spectra were scanned in mid-IR range, $600 \mathrm{~cm}^{-1}$ to $4000 \mathrm{~cm}^{-1}$, with a resolution of 4 $\mathrm{cm}^{-1}$. Sixty-four scans were coded for each spectrum and the spectra were ratioed against a background spectrum. Deconvolution of normal and malignant tissue spectra was performed and the second power derivative was also obtained.

\section{RESULTS AND DISCUSSION}

The spectra of the normal breast and the malignant breast tissues were recorded in frequency range $700 \mathrm{~cm}^{-1}-3850 \mathrm{~cm}^{-1}$. The spectra of the normal and the malignant tissues of different patients were compared and one of the typical cases is shown here. The malignant cells show appreciable biochemical deviations from their normal forebears in all the cases (Figure 1). The spectra of the normal tissues showed welldefined spectral features, while the spectra of the malignant tissues appeared to be more complicated. In order to isolate broad overlapping absorption bands and the baseline difference due to the change in the optical properties of biological tissue, calculation of second derivative spectra becomes important.

The spectrum of the malignant tissue showed a strong peak at $1076 \mathrm{~cm}^{-1}$, which was present only as a shoulder at $1097 \mathrm{~cm}^{-1}$ in the spectrum of the normal tissues (Figure 2). The absorption was attributed to symmetric phosphate $\left(\mathrm{v}_{\mathrm{s}} \mathrm{PO}_{2^{-}}\right)$stretching vibrational modes of phosphate $\left(\mathrm{PO}_{2}^{-}\right)$groups, contributed largely by nucleic acids in the breast tissues. The protein region of the spectra $\left(1300-1800 \mathrm{~cm}^{-1}\right)$ showed significant variations in the profiles of the normal and the malignant tissues. Another obvious difference between the spectra of the normal and the malignant tissues was in the glycogen-associated band at $1157 \mathrm{~cm}^{-1}$. The absorption was almost absent in the malignant tissues suggesting a marked decrease in the glycogen level of the breast tissues during malignancy. The spectral features were indicative of increased DNA and decreased protein content in the malignant samples.

It emerges from the above discussion that the IR spectral features hence the chemical composition of normal breast tissues was significantly different from cancerous tissues. 


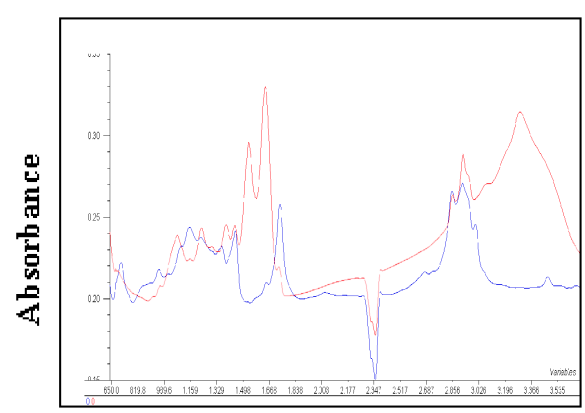

Wavenumber $\mathbf{c m}^{-1}$

Figure 1. Overlaid spectra of normal and malignant tissues

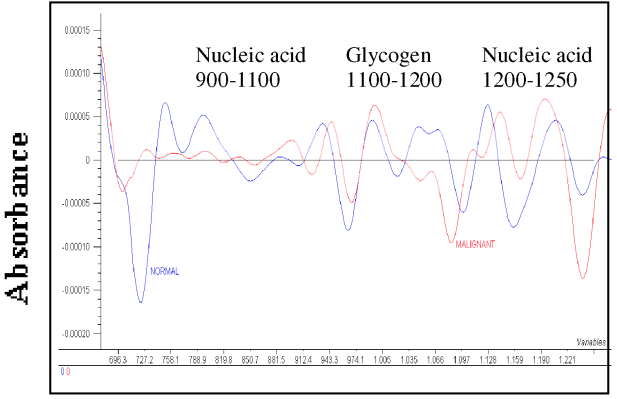

Wavenumber $\mathrm{cm}^{-1}$

Figure 2. Overlaid second order spectra of normal and malignant tissues

\section{CONCLUSIONS}

The results of the present study have shown that remarkable differences exist between the spectra of the normal and the infiltrating ductal carcinoma tissues in terms of spectral profiles and absorption frequencies of prominent absorption bands. The spectral differences reflect the changes in the content, conformation and composition of the nucleic acid and protein in the cells. The results are in accordance with histopathological observations such as nucleus condensation in cancerous tissues. Differences in the intrinsic biochemical composition are reflected in their mid-IR spectra and the spectra are highly characteristic of the tissue's state. With the use of statistical techniques, these signatures may form a basis for staging the disease.

\section{ACKNOWLEDGEMENT}

The authors thank the Director, National Physical Laboratory, New Delhi, India for giving permission to publish this paper. Financial support from Department of Science and Technology, New Delhi is thankfully acknowledged.

\section{REFERENCES}

1. M. Jackson and H. H. Mantsch, "FTIR Spectroscopy in Clinical Sciences," in Biomedical Applications of Spectroscopy, edited by R. J. H. Clark and R. E. Hester (John Wiley \& Sons Inc., U.S.A.) 1996, pp. 185.

2. P. T. Wong, S. M. Goldstein, R. C. Grekin, A. Godwin, C. Pivik and B. Rigas, Cancer Res 53, 762765 (1993).

3. B. Rigas and P. Wong, Cancer Res. 52, 84-88 (1992).

4. J. G. Wu, Y. Z. Xu, C. W. Sun, R. D. Soilvay, D. F. Xu, Q. G. Sun, S. F. Weng and G. X. Xu, Biopolymers 621, 185-192 (2001).

5. H. Fabian, P. Lasch, M. Boese and W. Haensh, Biopospectroscopy 67, 354-357 (2002). 